\title{
Herdabilidades e correlações entre caracteres de linhagens de feijão obtidas em monocultivo e em consórcio com o milho
}

\author{
Heriditys and correlation between characters of lines of beans obtained in \\ monocropping and intercropping with maize
}

\author{
Ângela Maria Quintão Lana ${ }^{1}$ Antônio Américo Cardoso ${ }^{2}$ Cosme Damião Cruz ${ }^{3}$
}

\section{RESUMO}

\begin{abstract}
Foram realizados os cruzamentos entre 'Ouro 1919' x 'Ouro Negro 1992', 'Ouro 1919' x Raça D e 'Ouro 1919' x Phaseolus aborigineus 283, com o objetivo de estimar as herdabilidades, no sentido amplo e as correlações fenotípica e genotípica da produtividade de grãos e seus componentes de rendimento, nos sistemas de monocultivo e de consórcio com a cultura do milho nas épocas de semeadura das "águas" e da "seca'. Para obtenção dessas estimativas, utilizaram-se, no ensaio de campo, as populações, $F_{1}, F_{2}$ e $F_{3}$ e seus genitores. As populações segregantes foram conduzidas pelo método de melhoramento "Single Seed Descent" (SSD). De modo geral, os coeficientes de herdabilidade foram maiores no sistema de consórcio do que no monocultivo. Entre os caracteres estudados, as maiores herdabilidades foram, de modo geral, obtidas para o número de vagens por planta. Os coeficientes de correlação entre os caracteres avaliados, em cada sistema de cultivo, mostraram que, no caso de seleção no monocultivo visando semeadura no consórcio, o número de vagens por planta é o caráter com maior potencial a ser utilizado no processo seletivo.
\end{abstract}

Palavras-chave: Phaseolus vulgaris L., Zea mays L., sistemas de cultivo, single seed descent, seleção.

\section{ABSTRACT}

Hybrids from 'Ouro 1919' x 'Ouro Negro 1992', 'Ouro 1919' x Raça D and 'Ouro 1919'x Phaseolus aborigineus 283, beans were obtained to study heritability and genetic correlations between some yield responses, in two crop systems namely monocropping and intercropping with maize during both dry and rainy season ${ }^{\text {s. All estimates }}$ were obtained through field data of $F_{1} F_{2}$ and $F_{3}$ populations as well as those of their original parents. Main populations were defined by the Single Seed Descent (SSD) method. Heritabilities estimated under intercropping conditions were often higher than those under monocropping system. Among all studied responses the highest heritabilities corresponded to the number of legumes per plant. Genetic correlation coefficients within systems suggest that the selection procedure should mainly consider the number of legumes per plant when selecting under monocropping system aiming further intercropping use.

Key words: Phaseolus vulgaris L., Zea mays L., culture systems, single seed descent, selection.

\section{INTRODUÇÃO}

Dentre os sistemas consorciados, a associação cultural de milho (Zea mays $L$.) com o feijão (Phaseolus vulgaris $\boldsymbol{L}$.) é o mais comum entre os agricultores. Na América Latina, quantidades superiores a $70 \%$ da produção de feijão são obtidas em sistema de consórcio (VIEIRA, 1989). Entretanto, todas as variedades de milho e de feijão disponíveis foram obtidas em programas de melhoramento realizados em monocultivo (RAMALHO, 1988). Por isso, iniciadas as pesquisas com o consórcio, uma das maiores preocupações foi estudar a existência de interação das variedades nos dois sistemas de cultivo.

${ }^{1}$ Engenheiro Agrônomo, Doutor, Professor Adjunto, Departamento de Zootecnia, Universidade Federal de Minas Gerais, CP 567, Belo Horizonte, MG. E-mail:lana@vet.ufmg.br. Autor para correspondência.

${ }^{2}$ Engenheiro Agrônomo, Doutor, Professor Aposentado, Departamento de Fitotecnia, Universidade Federal de Viçosa.

${ }^{3}$ Engenheiro Agrônomo, Doutor, Professor Titular, Departamento de Biologia Geral, UFV. 
Ensaios de adaptação de variedades de feijão têm mostrado que ocorre acentuada interação de variedades por ambientes (SANTOS et al., 1982; PACOVA et al., 1987). Essa interação também foi verificada em ensaios de progênies, evidenciando a necessidade de avaliação em vários ambientes (ABREU, 1989; TAKEDA, 1990).

As seleções têm sido realizadas somente em monocultivo, supondo que ocorrerá progresso correlacionado no consórcio. Para verificar a necessidade de um programa específico de melhoramento, para cultivo em consórcio, é importante saber como é a herdabilidade da produtividade de grãos e dos caracteres que afetam diretamente a produtividade, em cada um dos sistemas de cultivo. A herdabilidade pode ser afetada pela interação, já que é definida como o quociente entre a variância genética e a variância fenotípica. Assim, ocorrerá diferença entre o ganho esperado e o realizado com a seleção, pois o progresso esperado é diretamente proporcional à herdabilidade.

Resultados de trabalhos de ZIMMERMANN et al. (1984) e PETERNELLI et al. (1994) comparando estimativas de herdabilidades nos dois sistemas de cultivo, mostraram estimativas de herdabilidades no consórcio superiores às do monocultivo. Entretanto, resultados contraditórios foram obtidos por FURTADO et al. (1992). Informações sobre correlações entre produção de grãos e componentes de rendimento, bem como entre os componentes, são também importantes, pois pouco se conhece acerca do efeito do consórcio sobre essas correlações (ZIMMERMANN et al., 1984). Correlações fenotípicas e genotípicas entre a produtivadade de grãos e cada um dos seus componentes de rendimento, nos dois sistemas de cultivo, foram positivas, tendo sido as correlações entre a produtividade e o número de vagens por plantas as mais elevadas, variando de 88,2 a $96,12 \%$ (PETERNELLI et al., 1994).

Considerando esses aspectos, o presente trabalho foi realizado com os objetivos de estimar e comparar as herdabilidades, no sentido amplo e as correlações da produtividade de grãos de feijão e seus componentes de rendimento, em diferentes ambientes de cultivo.

\section{MATERIAL E MÉTODOS}

As populações segregantes, que deram origem às progênies, são resultantes dos cruzamentos 'Ouro 1919’ x ‘Ouro Negro 1992', 'Ouro 1919’ x Raça D e 'Ouro 1919’ x Phaseolus aborigineus 283.
O cultivar de feijão Ouro 1919 apresenta hábito de crescimento indeterminado, com hastes curtas, grãos de cor creme e flores brancas, e o Ouro Negro 1992, hábito de crescimento indeterminado, semitrepador, grãos pretos e flores de cor violeta. Ambos os cultivares são originários da raça Mesoamérica. A Raça D (durango) apresenta hábito de crescimento indeterminado, semitrepador, com grãos de tamanho médio originários do norte do México (GEPTS et al., 1988). O Phaseolus aborigineus 283 é um genótipo silvestre, revela crescimento indeterminado, ramas muito longas e finas, flores pequenas e violetas, grãos pequenos e rajados, encontrado com freqüência na região mesoamericana. O 'Ouro 1919' foi usado como fêmea por apresentar flores de cor branca, caráter recessivo. Com base nesse marcador morfológico, foi feita a eliminação de plantas oriundas de autofecundação na geração $\mathrm{F}_{1}$.

Os grãos $\mathrm{F}_{2}$ obtidos em cada cruzamento foram divididas em quatro partes contendo 600 sementes cada uma para serem semeadas nos sistemas de monocultivo e de consórcio com a cultura do milho, nas épocas de plantio das "águas" e da "seca". As gerações $\mathrm{F}_{2}$ e $\mathrm{F}_{3}$ foram desenvolvidas nesses ambientes por meio do método de melhoramento genealógico modificado "Single Seed Descent" (SSD), descrito por BRIM (1966) havendo, durante o avanço das gerações, a atuação de diferentes condições de ambiente na recombinação de gametas para formação de genótipos.

No consórcio, foi utilizado o milho híbrido Ag 1051, semeado no espaçamento de $1 \mathrm{~m}$ entre fileiras e densidade de 40.000 plantas por hectare. Na época das "águas", as populações segregantes de feijão foram semeadas nas fileiras de milho e, na "seca", foram semeadas duas fileiras de feijão entre cada fileira de milho. Nas duas épocas de plantio, foram utilizadas 10 sementes de feijão por metro de sulco. As populações avançadas no consórcio sofreram, alternadamente, a ação de dois tipos de seleção natural, já que o milho encontrava-se em estádios de desenvolvimento diferentes nas épocas das "águas" e da "seca", o que proporcionou ao feijão ambientes distintos nessas duas épocas de plantio. No monocultivo, tanto na época das "águas" quanto na da "seca", o feijão foi semeado no espaçamento de $0,5 \mathrm{~m}$ entre fileiras, com 10 sementes por metro de sulco.

Coletaram-se os seguintes dados em plantas individuais: número de vagens por planta (NVP), o número de grãos por vagem (NGV) e peso médio de 100 grãos (P100G) e a produtividade de grãos por planta (PROD), expressa em gramas.

Para obtenção das estimativas das herdabilidades, no sentido amplo, utilizou-se a expressão: 


$$
H_{a}=\frac{V(G)}{V(F)}
$$

$\mathrm{H}_{\mathrm{a}}$ : herdabilidade, no sentido amplo, de plantas individuais nas populações $F_{2}$ ou $F_{3}$.

$\mathrm{V}(\mathrm{G})$ : estimador da variância genotípica de populações $F_{2}$ ou $F_{3}$.

$\mathrm{V}(\mathrm{F})$ : estimador da variância fenotípica nas populações $F_{2}$ ou $F_{3}$.

A estimativa da variância genotípica foi obtida pela diferença entre as variâncias nas gerações $\mathrm{F}_{2} \mathrm{ou} \mathrm{F}_{3} \mathrm{e}$ as variâncias dos genitores e $\mathrm{F}_{1}$. As variâncias fenotípicas foram calculadas com base nas variâncias encontradas nas gerações $\mathrm{F}_{2}$ ou $\mathrm{F}_{3}$; as de ambientes foram calculadas com base nas variâncias encontradas nas gerações dos genitores e $F_{1}$. Foi considerada a proporção de $1 / 2$ e $1 / 4$ para a geração $F_{1}$ e de $1 / 4$ e para cada um dos genitores nas gerações $\mathrm{F}_{2}$ e $\mathrm{F}_{3}$, respectivamente.

Os coeficientes de correlação foram estimados pela seguinte fórmula (FALCONER, 1987).

$$
r=\frac{\operatorname{cov}(x y)}{[v(x) \cdot v(y)] \frac{1}{2}}, \text { em que: }
$$
genotípica.

$r=$ coeficiente de correlação fenotípica ou

$\operatorname{cov}(x, y)=$ covariância fenotípica ou genotípica, dos caracteres $\mathrm{x}$ e $\mathrm{y}$.

$\mathrm{v}(\mathrm{x})$ e $\mathrm{v}(\mathrm{y})=$ variância fenotípica ou genotípica, dos caracteres $\mathrm{x}$ e $\mathrm{y}$, respectivamente.

As covariâncias fenotípicas foram calculadas com base nas variâncias encontradas nas gerações $\mathrm{F}_{2}$ ou $\mathrm{F}_{3} \mathrm{e}$, as de ambiente foram estimadas com base nas variâncias encontradas nas gerações dos genitores e $F_{1}$, considerando as mesmas proporções das variâncias encontradas nas gerações $\mathrm{F}_{2}$ ou $\mathrm{F}_{3} \mathrm{e}$ genitores na estimação das herdabilidades. As covariâncias genotípicas foram calculadas pela diferença entre as covariâncias fenotípica e de ambiente para cada par de caracteres.

\section{RESULTADOS E DISCUSSÃO}

Nas épocas das "Águas" e da "Seca", as herdabilidades das gerações $F_{2}$ e $F_{3}$ foram maiores no consórcio do que no monocultivo para os caracteres avaliados, com exceção de peso de 100 grãos e número de vagens por planta das gerações F2 e F3, respectivamente, na época das "águas" (Tabela 1). Estes resultados parecem contrariar o que seria esperado, já que o monocultivo, normalmente, proporciona um ambiente mais uniforme e permite maior expressão da herdabilidade. Entretanto, herdabilidades superiores no consórcio têm sido verificadas, como as obtidas por ZIMMERMANN et al. (1984), que encontraram estimativas de herdabilidades de rendimento de grãos, calculadas com base em progênies $F_{4}$ e $F_{5}$ de três cruzamentos distintos, variando entre 35 e $89 \%$ no consórcio e de 28 a $80 \%$ no monocultivo. Resultados semelhantes foram obtidos por PETERNELLI et al. (1994), trabalhando com linhagens obtidas do cruzamento 'Ouro 1919' x 'Ouro Negro 1992', onde verificaram estimativas de herdabilidades para produtividade de grãos e seus componentes, no sentido restrito, maiores no cultivo em consórcio (de $43,98 \%$ a $67,47 \%$ ) do que no monocultivo (de $30,80 \%$ a $56,14 \%$ ). Estes dados evidenciam a possibilidade de obtenção de maiores ganhos com a seleção no consórcio, ou seja, a capacidade do genótipo em transmitir os caracteres genéticos mais intensamente, em condições de estresse de ambiente.

Observa-se, de modo geral, que as herdabilidades do número de vagens por planta foram superiores às da produtividade de grãos (Tabela 1). Isso mostra que a produtividade de grãos é um caracter controlado por um número de genes maior do que o número de vagens por planta, indicando que a produtividade de grãos é muito influenciada pelas condições de ambiente e, portanto, de manuseio mais difícil. Portanto, no processo seletivo maiores cuidados devem ser tomados, principalmente no que se refere à geração em que se dará esse processo.

As herdabilidades do peso de 100 grãos mostraram-se muito variáveis, ora superior à herdabilidade da produtividade de grãos, ora inferior. Todas as herdabilidades obtidas para o número de grãos por vagem, com exceção do cruzamento 'Ouro 1919' x 'Ouro Negro 1992', na geração F do consórcio na época da "Seca", foram inferiores às herdabilidades da produção de grãos (Tabela 1). Resultados semelhantes foram obtidos por PETERNELLI et al. (1994), enquanto dados opostos foram encontrados por PEREIRA (1984) e SANTOS et al. (1985). Os resultados encontrados por esses últimos autores reforçam a idéia de que a produtividade de grãos é o caráter mais influenciado pelas variações de ambiente.

Na tabela 1, verifica-se, no monocultivo, que as herdabilidades na geração $F_{3}$ aumentaram somente nos caracteres número de vagens por planta e produtividade de grãos do cruzamento ‘Ouro 1919' x 'Ouro Negro 1992' e no número de vagens por planta do cruzamento 'Ouro 1919' x Phaseolus aborigineus 283. Já no consórcio, as herdabilidades na geração $F_{3}$ foram superiores à $F_{2}$ apenas nos caracteres produtividade de grãos e peso de 100 grãos dos cruzamentos entre 'Ouro 1919' x Raça D e 'Ouro 1919' 
Tabela 1 - Estimativas de Herdabilidades dos Caracteres Produtividade (PROD), Número de vagens por planta (NVP), Número de grãos por vagem (NGV) e Peso de 100 grãos (P100G) nas gerações $F_{2}$ e $F_{3}$ dos Cruzamentos 'Ouro 1919' x 'Ouro Negro 1992' (Cruz. 1), 'Ouro 1919' x Raça D (Cruz.2) e 'Ouro 1919' x Phaseolus aborigineus 283 (Cruz. 3) Obtidas em semeadura nas épocas das "Águas" e da "Seca", na Universidade Federal de Viçosa em 1999.

\begin{tabular}{|c|c|c|c|c|c|c|}
\hline \multirow{2}{*}{ Caracteres } & \multicolumn{3}{|c|}{ Geração $F_{2}$} & \multicolumn{3}{|c|}{ Geração $F_{3}$} \\
\hline & Cruz. 1 & Cruz. 2 & Cruz. 3 & Cruz. 1 & Cruz. 3 & Cruz. 3 \\
\hline \multicolumn{7}{|l|}{$\begin{array}{l}\text { "Águas" } \\
\text { Monocultivo }\end{array}$} \\
\hline PROD & 0,49 & 0,67 & $*$ & 0,57 & 0,64 & 0,71 \\
\hline NVP & 0,58 & 0,78 & 0,68 & 0,71 & 0,66 & 0,84 \\
\hline NGV & 0,36 & $*$ & 0,14 & 0,16 & 0,03 & $*$ \\
\hline P100G & 0,68 & 0,69 & 0,72 & 0,02 & 0,66 & 0,60 \\
\hline \multicolumn{7}{|l|}{ Consórcio } \\
\hline PROD & 0,79 & 0,67 & 0,27 & 0,60 & 0,71 & 0,82 \\
\hline NVP & 0,82 & 0,81 & 0,76 & 0,69 & 0,75 & 0,53 \\
\hline NGV & $*$ & $*$ & 0,25 & 0,28 & 0,38 & 0,16 \\
\hline P100G & 0,68 & 0,43 & 0,50 & * & 0,71 & 0,96 \\
\hline \multicolumn{7}{|l|}{$\begin{array}{l}\text { "Seca" } \\
\text { Monocultivo }\end{array}$} \\
\hline PROD & 0,76 & 0,63 & 0,55 & 0,48 & 0,24 & 0,54 \\
\hline NVP & 0,73 & 0,68 & 0,79 & 0,51 & 0,38 & 0,73 \\
\hline NGV & 0,43 & 0,11 & 0,28 & $*$ & $*$ & $*$ \\
\hline P100G & 0,95 & 0,52 & 0,49 & $*$ & $*$ & $*$ \\
\hline \multicolumn{7}{|l|}{ Consórcio } \\
\hline PROD & 0,81 & 0,82 & 0,75 & 0,58 & 0,53 & 0,62 \\
\hline NVP & 0,83 & 0,84 & 0,91 & 0,56 & 0,48 & 0,73 \\
\hline NGV & 0,88 & $*$ & 0,61 & 0,55 & 0,27 & 0,56 \\
\hline P100G & 0,99 & 0,94 & 0,65 & 0,93 & 0,41 & 0,63 \\
\hline
\end{tabular}

* Estimativa da herdabilidade menor do que zero.

x Phaseolus aborigineus 283. Na época da "Seca" as herdabilidades na geração $\mathrm{F}_{3}$ foram inferiores à geração $\mathrm{F}_{2}$ em todos os caracteres avaliados, nos dois sistemas de cultivo. Segundo FALCONER (1987), a estimativa da herdabilidade aumenta à medida que se sucedem as gerações de autofecundações. No presente trabalho não se observou aumento dos coeficientes de herdabilidade da geração $F_{2}$ para $F_{3}$, possivelmente em virtude da magnitude das variações de ambiente ocorridas nas diferentes épocas de semeadura.

De modo geral, nas gerações $\mathrm{F}_{2}$ e $\mathrm{F}_{3}$ desenvolvidas no monocultivo e no consórcio, na época das "águas", as correlações, genéticas e fenotípicas entre os caracteres apresentaram baixos valores, com exceção das correlações entre a produtividade de grãos e o número de vagens por planta $(r=0,84$ a 1,00). Na época da "Seca", comportamento semelhante foi observado tanto no monocultivo quanto no consórcio, para os três cruzamentos (Tabelas 2, 3 e 4). Vários autores, entre eles, RAMALHO et al. (1979); SANTOS (1981); PEREIRA (1984); NIENHUIS \& SINGH (1986); CASTOLDI (1990) \& PETERNELLI et al. (1994), relatam que o número de vagens por planta é o componente com maior participação na produtividade de grãos do feijoeiro, visto que as correlações genéticas e fenotípicas entre a produção de grãos e o número de vagens por planta foram positivas a quase sempre elevadas.

No caso das correlações fenotípicas e genotípicas da produtividade de grãos com o número de grãos por vagem e da produtividade de grãos com o peso de 100 grãos, verificou-se que, em geral, os valores foram baixos e positivos, variando de 0,03 a 0,40 (Tabelas 2, 3 e 4). Os coeficientes de correlação entre a produtividade de grãos e esses componentes primários de produtividade, relacionados na literatura, são amplamente variáveis. Foram observados, com freqüência, coeficientes de correlação negativos entre esses componentes. Esses resultados podem ser ocasionados pela alta competição entre plantas, por causa de fatores de ambientes, o que torna também intensa a competição entre as diferentes partes da planta por nutrientes e metabólitos, sendo esta particularmente expressiva durante a fase de formação das estruturas reprodutivas, o que conduz a uma variação compensatória entre os componentes primários de produtividade de grãos.

As correlações genéticas e fenotípicas entre a produtividade de grãos e o número de vagens por planta foram maiores no monocultivo (de 0,87 a 1,00) do que no consórcio (de 0,65 a 0,98 ), em todos os cruzamentos (Tabelas 2, 3 e 4). Esta variação pode ter ocorrido por causa da ação de agentes seletivos naturais favorecendo genótipos mais ajustados, para esses caracteres, no monocultivo. Observa-se, ainda, que houve uma tendência de as correlações genéticas e fenotípicas entre os caracteres apresentarem valores superiores na geração $F_{3} \mathrm{em}$ relação à F $F_{2}$, exceto para o cruzamento 'Ouro 1919' x Phaseolus aborigineus 283, nos dois sistemas de semeadura, nas épocas das "águas" e da "seca". Estes resultados podem ter ocorrido em razão do aumento da variância genética total da geração $\mathrm{F}_{2}$ para a geração $\mathrm{F}_{3}$ (FALCONER, 1987).

As correlações genotípicas foram maiores que as fenotípicas em $83,33 \%$ dos casos observados, para os caracteres número de vagens por planta e produtividade de grãos, concordando com os resultados obtidos por SANTOS (1981) e 
Tabela 2 - Estimativas de Coeficientes de Correlação Fenotípica (F) e Genotípica (G) entre os Caracteres Produtividade de Grãos/Planta (PROD), Número de Vagens/Planta (NVP), Número de Grãos/Vagem (NGV) e Peso Médio de 100 Grãos (P100G) nas Gerações $\mathrm{F}_{2}$ e $\mathrm{F}_{3}$ do Cruzamento do Feijão 'Ouro 1919' x 'Ouro Negro 1992' Obtidas em semeadura nas Épocas das "Águas" e "Seca", na Universidade Federal de Viçosa em 1999.

\begin{tabular}{|c|c|c|c|c|c|c|c|c|c|c|}
\hline \multicolumn{3}{|c|}{ Caracteres } & \multicolumn{4}{|c|}{ Época das "Águas" } & \multicolumn{4}{|c|}{ Época da "Seca" } \\
\hline & & & PROD & NVP & NGV & P100G & PROD & NVP & NGV & P100G \\
\hline \multirow{8}{*}{$\mathrm{F} 2$} & PROD & $\mathrm{F}$ & & 0,91 & 0,18 & 0.38 & & 0,91 & 0,43 & 0,06 \\
\hline & & G & & 1,00 & 0,14 & 0.36 & & 0,94 & 0,45 & 0,04 \\
\hline & NVP & $\mathrm{F}$ & 0,86 & & $-0,06$ & 0.25 & 0,90 & & 0,20 & $-0,06$ \\
\hline & & G & 0,90 & & $-0,08$ & 0.26 & 0,91 & & 0,34 & $-0,07$ \\
\hline & NGV & $\mathrm{F}$ & 0,35 & 0,00 & & -0.16 & 0,19 & 0,07 & & $-0,07$ \\
\hline & & G & $*$ & $*$ & & -0.27 & 0,16 & 0,06 & & $-0,13$ \\
\hline & P100G & $\mathrm{F}$ & 0,36 & 0,12 & 0,02 & & 0,09 & $-0,07$ & $-0,05$ & \\
\hline & & G & 0,42 & 0,09 & $*$ & & 0,08 & $-0,09$ & $-0,05$ & \\
\hline \multirow{8}{*}{ F3 } & PROD & $\mathrm{F}$ & & 0,93 & 0,22 & 0,25 & & 0,92 & 0,26 & 0,18 \\
\hline & & G & & 1,00 & $-0,14$ & 0,27 & & 1,00 & $*$ & 0,03 \\
\hline & NVP & $\mathrm{F}$ & 0,90 & & 0,03 & 0,11 & 0,91 & & 0,09 & 0,06 \\
\hline & & G & 0,95 & & $-0,30$ & 0,95 & 0,91 & & $*$ & 0,02 \\
\hline & NGV & $\mathrm{F}$ & 0,16 & $-0,09$ & & $-0,20$ & 0,34 & 0,12 & & $-0,43$ \\
\hline & & G & $-0,06$ & $-0,20$ & & $-0,40$ & 0,27 & 0,06 & & $-0,50$ \\
\hline & P100G & $\mathrm{F}$ & 0,14 & $-0,05$ & $-0,15$ & & 0,13 & 0,04 & $-0,27$ & \\
\hline & & G & $*$ & $*$ & 0,00 & & 0,15 & 0,07 & $-0,36$ & \\
\hline
\end{tabular}

Valores acima e abaixo da diagonal se referem a monocultivo e consórcio, respectivamente.

* Variância genética menor do que zero.

Tabela 3 - Estimativas de Coeficientes de Correlação Fenotípica (F) e Genotípica (G) entre os Caracteres Produtividade de Grãos/Planta (PROD), Número de Vagens/Planta (NVP), Número de Grãos/Vagem (NGV) e Peso Médio de 100 Grãos (P100G) nas Gerações $\mathrm{F}_{2} \mathrm{e}_{3} \mathrm{~F}_{3}$ do Cruzamento Feijão 'Ouro 1919' x Raça D Obtidas em Semeadura nas Épocas das "Águas" e "Seca", na Universidade Federal de Viçosa em 1999.

\begin{tabular}{|c|c|c|c|c|c|c|c|c|c|c|}
\hline \multirow{2}{*}{\multicolumn{3}{|c|}{ Caracteres }} & \multicolumn{4}{|c|}{ Época das "Águas" } & \multicolumn{4}{|c|}{ Época da "Seca" } \\
\hline & & & \multirow{2}{*}{ PROD } & \multirow{2}{*}{$\frac{\text { NVP }}{0,92}$} & \multirow{2}{*}{$\frac{\mathrm{NGV}}{0,39}$} & \multirow{2}{*}{$\frac{\mathrm{P} 100 \mathrm{G}}{0,32}$} & \multirow[t]{2}{*}{ PROD } & \multirow{2}{*}{$\frac{\text { NVP }}{0,92}$} & \multirow{2}{*}{$\frac{\mathrm{NGV}}{0,40}$} & \multirow{2}{*}{$\frac{\text { P100G }}{0,09}$} \\
\hline \multirow{8}{*}{$\mathrm{F} 2$} & PROD & $\mathrm{F}$ & & & & & & & & \\
\hline & & G & & 0,96 & - & 0,32 & & 0,99 & 0,36 & 0,09 \\
\hline & NVP & $\mathrm{F}$ & 0,85 & & 0,14 & 0,17 & 0,82 & & 0,18 & $-0,06$ \\
\hline & & G & 0,88 & & $*$ & 0,14 & 0,84 & & 0,60 & $-0,04$ \\
\hline & NGV & $\mathrm{F}$ & 0,38 & 0,02 & & 0,02 & 0,34 & 0,10 & & $-0,26$ \\
\hline & & G & $*$ & $*$ & & $*$ & $*$ & $*$ & & $-0,60$ \\
\hline & P100G & $\mathrm{F}$ & 0,29 & 0,07 & $-0,01$ & & 0,36 & 0,01 & $-0,14$ & \\
\hline & & G & 0,25 & 0,01 & $*$ & & 0,39 & 0,01 & $*$ & \\
\hline \multirow{8}{*}{ F3 } & PROD & $\mathrm{F}$ & & 0,89 & 0,46 & 0,22 & & 0,93 & 0,32 & 0,13 \\
\hline & & G & & 0,90 & 0,59 & 0,18 & & 1,00 & * & 0,03 \\
\hline & NVP & $\mathrm{F}$ & 0,87 & & 0,24 & $-0,04$ & 0,92 & & 0,08 & 0,00 \\
\hline & & G & 0,91 & & 0,03 & $-0,09$ & 0,98 & & $*$ & 0,02 \\
\hline & NGV & $\mathrm{F}$ & 0,29 & 0,04 & & $-0,03$ & 0,26 & 0,04 & & $-0,30$ \\
\hline & & G & 0,21 & 0,06 & & $-0,52$ & 0,03 & 0,02 & & $-0,50$ \\
\hline & P100G & $\mathrm{F}$ & 0,22 & 0,02 & $-0,19$ & & 0,19 & 0,05 & $-0,25$ & \\
\hline & & G & 0,24 & 0,09 & $-0,30$ & & 0,25 & 0,22 & $-0,44$ & \\
\hline
\end{tabular}

Valores acima e abaixo da diagonal se referem a monocultivo e consórcio, respectivamente.

*Variância genética menor do que zero.

Ciência Rural, v. 33, n. 6, nov-dez, 2003. 
Tabela 4 - Estimativas de Coeficientes de Correlação Fenotípica (F) e Genotípica (G) entre os Caracteres Produtividade de Grãos/Planta (PROD), Número de Vagens/Planta (NVP), Número de Grãos/Vagem (NGV) e Peso Médio de 100 Grãos (P100G) nas Gerações $\mathrm{F}_{2}$ e $\mathrm{F}_{3}$ do Cruzamento Feijão 'Ouro 1919' x Phaseolus aborigineus 283 Obtidas em semeadura nas Épocas das "Águas" e "Seca", na Universidade Federal de Viçosa em 1999.

\begin{tabular}{|c|c|c|c|c|c|c|c|c|c|c|}
\hline \multirow{2}{*}{\multicolumn{2}{|c|}{ Caracteres }} & & \multicolumn{4}{|c|}{ Época das "Águas" } & \multicolumn{4}{|c|}{ Época da "Seca" } \\
\hline & & & \multirow[t]{2}{*}{ PROD } & \multirow{2}{*}{$\frac{\text { NVP }}{0,87}$} & \multirow{2}{*}{$\frac{\mathrm{NGV}}{0,32}$} & \multirow{2}{*}{$\frac{\mathrm{P} 100 \mathrm{G}}{0,32}$} & \multirow[t]{2}{*}{ PROD } & \multirow{2}{*}{$\frac{\text { NVP }}{0,89}$} & \multirow{2}{*}{$\frac{\mathrm{NGV}}{0,38}$} & \multirow{2}{*}{$\frac{\mathrm{P} 100 \mathrm{G}}{0,21}$} \\
\hline \multirow{8}{*}{$\mathrm{F} 2$} & PROD & $\mathrm{F}$ & & & & & & & & \\
\hline & & $\mathrm{G}$ & & * & 0,03 & $-0,03$ & & 0,97 & 0,28 & 0,23 \\
\hline & NVP & $\mathrm{F}$ & 0,84 & & 0,06 & 0,12 & 0,87 & & 0,14 & 0,01 \\
\hline & & G & 1,00 & & 0,06 & 0,12 & 0,90 & & 0,33 & 0,05 \\
\hline & NGV & $\mathrm{F}$ & 0,10 & 0,19 & & $-0,08$ & 0,43 & 0,12 & & $-0,27$ \\
\hline & & G & $-0,90$ & $-0,41$ & & $-0,20$ & 0,48 & 0,17 & & $-0,62$ \\
\hline & $\mathrm{P} 100 \mathrm{G}$ & $\mathrm{F}$ & 0,27 & 0,06 & $-0,12$ & & 0,26 & 0,01 & 0,04 & \\
\hline & & G & 0,26 & $-0,07$ & $-0,03$ & & 0,19 & 0,04 & 0,23 & \\
\hline \multirow{8}{*}{ F3 } & PROD & $\mathrm{F}$ & & 0,84 & 0,35 & 0,45 & & 0,85 & 0,43 & 0,23 \\
\hline & & G & & 0,82 & $*$ & 0,57 & & 0,87 & $*$ & $-0,03$ \\
\hline & NVP & $\mathrm{F}$ & 0,67 & & 0,14 & 0,24 & 0,84 & & 0,22 & $-0,01$ \\
\hline & & G & 0,65 & & $*$ & 0,33 & 0,76 & & $*$ & $-0,04$ \\
\hline & NGV & $\mathrm{F}$ & 0,21 & 0,06 & & $-0,12$ & 0,33 & $-0,01$ & & $-0,10$ \\
\hline & & $\mathrm{G}$ & 0,16 & 0,06 & & $*$ & $-0,21$ & $-0,17$ & & $-0,50$ \\
\hline & P100G & $\mathrm{F}$ & 0,88 & 0,12 & 0,00 & & 0,36 & 0,22 & $-0,10$ & \\
\hline & & G & 0,98 & 0,18 & 0,05 & & 0,67 & 0,44 & $-0,06$ & \\
\hline
\end{tabular}

Valores acima e abaixo da diagonal se referem a monocultivo e consórcio, respectivamente.

* Variância genética menor do que zero.

PETERNELLI et al. (1994). Esse resultado indica que o número de vagens por planta é um caráter importante no melhoramento, com vistas ao aumento da produtividade de grãos por meio da seleção indireta.

\section{CONCLUSÕES}

Os coeficientes de herdabilidade foram maiores no consórcio do que no monocultivo. Entre os caracteres estudados, as maiores herdabilidades foram obtidas para o número de vagens por planta.

Os coeficientes de correlação entre os caracteres avaliados em cada sistema de cultivo mostraram que, no caso de seleção no monocultivo visando semeadura, no consórcio, o número de vagens por planta é o caráter com maior potencial a ser utilizado no processo seletivo.

\section{REFERÊNCIAS BIBLIOGRÁFICAS}

ABREU, A.F.B. Avaliação de progênies de feijoeiro do cruzamento 'Carioca 80' $x$ 'Rio Tibagi' em diferentes densidades de plantio. 1989. 63f. Dissertação (Mestrado em Agronomia) Curso de Pós-graduação em Agronomia, Escola Superior de Agricultura de Lavras, 1989.
BRIM, C.A. A modified pedigree method of selection in soybeans. Crop Science, Illinois, v.6, n.1, p.220, 1966.

CASTOLDI, F.L. Análise das interrelações entre rendimento e diversas características agronômicas do feijoeiro (Phaseolus vulgaris L.). 1990. 73f. Dissertação (Mestrado em Genética e Melhoramento) - Curso de Pós- graduação em Genética e Melhoramento, Universidade Federal de Viçosa.

FALCONER, D.S. Introdução à genética quantitativa. Viçosa : UFV, 1987. 279p.

FURTADO, M.R. et al. Linhagens de feijão obtidas no monocultivo e no consórcio com a cultura do milho e seu comportamento nesses sistemas de cultivo. Revista Ceres, Viçosa, v.39, n.223, p.276-289, 1992.

GEPTS, P.L. et al. Dissemination pathways of common bean, (Phaseolus vulgaris L., Fabaceae) deduced from phaseolin electrophoretic variability I. Economic Botany, The Americas, v.42, n.1, p.73-85, 1988.

NIENHUIS, J.; SINGH, S.P. Combining ability analysis and relationship among yield, yield components and architectural traits in dry bean. Crop Science, Illinois, v.26, n.1, p.21-27, 1986.

PACOVA, B.E.V. et al. Adaptação e estabilidade fenotípica de cultivares de feijão preto no estado do Espírito Santo. Pesquisa Agropecuária Brasileira, Brasília, v.22, n.5, p.485-490, 1987.

PEREIRA, T.N.S. Estimativas de parâmetros genéticos na identificação de genitores para o melhoramento do feijoeiro - 
comum. 1984. 55f. Dissertação (Mestrado em Genética e Melhoramento) - Curso de Pós-graduação em Genética e Melhoramento, Universidade Federal de Viçosa.

PETERNELLI, L.A. et al. Herdabilidades e correlações do rendimento do feijão e seus componentes primários no monocultivo e no consórcio. Revista Ceres, Viçosa, v.41, n.235, p.306-316, 1994.

RAMALHO, M.A.P.; ANDRADE, L.A.B.; TEIXEIRA, N.C.S Correlações genéticas e fenotípicas entre caracteres do feijão (Phaseolus vulgaris L.). Ciência e prática, Lavras, v.3, n.1, p.63-70, 1979

RAMALHO, M.A.P. Consórcio nas regiões sudeste e CentroOeste. In: ZIMMERMANN, M.J.O.; ROCHA, M.; YAMADA, T. Cultura do feijoeiro: fatores que afetam a produtividade. Piracicaba : Associação Brasileira para pesquisa do Potássio e do Fosfato, 1988. Cap.4, p.416-437.

SANTOS, J.B. dos; VELLO, N.A.; RAMALHO, M.A.P. Stability of grain yield and of its basic components in beans (Phaseolus vulgaris L.). Revista Brasileira de Genética, São Bernardo do Campo, v.4, n.4, p.761-772, 1982.
SANTOS, J.B. dos; VENCOVSKY, R.; RAMALHO, M.A.P. Controle genético da produção de grãos e seus componentes primários em feijoeiro. Pesquisa Agropecuária Brasileira, Brasília, v.10, n.10, p.1203-1211, 1985.

SANTOS, P.C. Herdabilidades e correlações do rendimento com seus componentes, em dois cruzamentos de feijão - comum (Phaseolus vulgaris L.). 1981. $60 \mathrm{f}$. Dissertação (Mestrado em Genética e Melhoramento) - Curso de Pós-graduação em Genética e Melhoramento, Universidade Federal de Viçosa

TAKEDA, C. Avaliação de progênies de feijoeiro do cruzamento 'ESAL 501' $x$ 'A 354' em diferentes ambientes. 1990. 82f. Dissertação (Mestrado em Agronomia) - Curso de Pós-graduação em Agronomia, Escola Superior de Agricultura de Lavras.

VIEIRA, C. O feijão em cultivos consorciados. Viçosa : UFV, 1989. 143p.

ZIMMERMANN, M.J.O.; ROSIELLE, A.A.; WAINES, J.G. Heritabilities of grain yield of common bean in sole crop and in intercrop with maize. Crop Science, Illinois, v.24, n.3, p.641-644, 1984. 